\title{
Use of Stem Cell Suspensions Containing Separated Fetal Stem Cells in Complex Treatment of Patients with Essential Hypertension
}

\author{
Klunnyk MO ${ }^{1 *}$, Sych NS ${ }^{1}$, Matiyashchuk IG ${ }^{1}$, Sinelnyk AA ${ }^{1}$, Ivankova OV ${ }^{1}$, Demchuk MP1 ${ }^{1}$ Skalozub MV ${ }^{2}$ and Sorochynska KI ${ }^{3}$
}

${ }^{1}$ Clinical Department, Cell Therapy Center EmCell, Kyiv City, Ukraine

${ }^{2}$ Laboratory and Biotechnology Department, Cell Therapy Center EmCell, Kyiv City, Ukraine

${ }^{3}$ Stem Cells Bank, Cell Therapy Center EmCell, Kyiv City, Ukraine

\begin{abstract}
Objective: To study a complex treatment including stem cell preparations with separated Fetal Stem Cells (FSCs) in suspensions and therapy effect on dynamics of arterial blood pressure in the patients with essential arterial hypertension.

Material and methods: Comparative study on 25 patients of the main group suffering from essential arterial hypertension was performed to investigate the effect of complex treatment with inclusion of preparations of FSCs in the suspensions containing extracted stem cells of fetal liver, brain and heart along with conventional therapy on a dynamics of $A B P$ ranges in the patients. Control Group included 25 patients with essential arterial hypertension who were compared to the patients in the main group based on all characteristics. The patients were studied before FSCs therapy, over 1, 3 and 6 months after treatment by use of separated FSCs.

Results: Increased regulation of vascular tone, better contractile function of the heart and enhanced excretory function of kidneys leading to decrease of Circulating Blood Volume (CBV), Cardiac Output (CO) and Total Peripheral Resistance (TPR) of vessels have been established in the patients. In addition, systolic function of LV myocardium was improved by way of increasing contractile cellular elements within myocardium and/or due to enhanced functional reserves of cardiomyocytes in the recipient.
\end{abstract}

Conclusion: FSCs therapy proved to be safe and highly effective in stabilization of systemic Arterial Blood Pressure (ABP) and contributed to better life quality among the patients with arterial hypertension.

Keywords: Essential arterial hypertension; Level of arterial blood pressure; Use of fetal stem cell suspensions in complex treatment

\begin{abstract}
Abbreviations: FSCs: Fetal Stem Cells; AH: Arterial Hypertension; ABP: Arterial Blood Pressure; SBP: Systolic Blood Pressure; DBP: Diastolic Blood Pressure; LV: Left Ventricle; LVMT: Left Ventricular Myocardial Thickness; PWV: Pulse Wave Velocity; PP: Pulse Pressure; Echo ECG: Echocardiography; CF: Cardiac Failure; CO: Cardiac Output; TPR: Total Peripheral Resistance; CBV: Circulating Blood Volume; GFR: Glomerular Filtration Rate; CKD: Chronic Kidney Disease; IHD: Ischemic Heart Disease; DMSO: Dimethyl Sulfoxide; HIV: Human Immunodeficiency Virus; CFU-E: Colony-forming Unit Erythrocyte; CFU-GM: Colony-forming Unit Granulocyte Monocyte; CFU-GEMM: Colony Forming Unit-Granulocyte, Erythrocyte, Monocyte, Megakaryocyte
\end{abstract}

\section{Introduction}

Cardiovascular diseases are known to hold the first place among the causes of death for the general population and stay among the main problems at the health care establishments in all economically developed countries worldwide [1]. In accordance with the data of World Health Organization (WHO) 17.3 millions of people suffering from cardiovascular diseases died in 2012 and their number constituted $30 \%$ among all cases of death throughout the world. A similar problem also refers to the countries with both low and high income rates to different extent. More than $80 \%$ of mortality cases in the countries with high income accrue to cardiovascular diseases; in particular, the mortality rates owing to the diseases above are almost similar both for women and men population. Approximately 23.6 million of individuals will be dying annually as a result of cardiovascular diseases until 2030; mainly these are patients with heart disease and stroke which are expected to be the principal causes of death in population
[2]. Nowadays, on the planet around $15 \%$ of individuals are suffering from Arterial Hypertension ( $\mathrm{AH})$, specifically their systolic arterial blood pressure is preserved at the level of $140 \mathrm{~mm}$. Hg. or even tends to exceed the range above and/or diastolic blood pressure in them can be as high as $90 \mathrm{~mm}$. Hg. in the least (without use of antihypertensive medicines).

Essential AH is a chronic illness with persistent and stable elevation of arterial blood pressure of unknown etiology as the principal clinical feature. According to the recommendations of WHO Systolic Blood Pressure (SBP) is referred to as increased if it exceeds or equals to 140 $\mathrm{mm}$. Hg., and when Diastolic Blood Pressure (DBP) - reaches $90 \mathrm{~mm}$. $\mathrm{Hg}$. or raises over this range [3].

A combination of adaptative and degenerative changes of the heart and vessels is among the pathological anatomy substrate which results in AH. Hypertrophy of the Left Ventricle (LV), hyperplasia as well as hypertrophy of nonstriated muscle cells in the internal and median membranes of vasculature belong to adaptative changes. Heart

*Corresponding author: Klunnyk MO, Clinical Department, Cell Therapy Center EmCell, Kyiv City, 37 A Syretska Street, Kyiv 04073, Ukraine, Tel: +38 06723627 61, +38 04422328 95; Fax: +38 04446880 29; E-mail: infocenter@emcell.com

Received October 26, 2016; Accepted November 21, 2016; Published November 28, 2016

Citation: Klunnyk MO, Sych NS, Matiyashchuk IG, Sinelnyk AA, Ivankova OV, et al. (2016) Use of Stem Cell Suspensions containing Separated Fetal Stem Cells in Complex Treatment of Patients with Essential Hypertension. J Stem Cell Res Ther 6: 366. doi: 10.4172/2157-7633.1000366

Copyright: (c) 2016 Klunnyk MO, et al. This is an open-access article distributed under the terms of the Creative Commons Attribution License, which permits unrestricted use, distribution, and reproduction in any medium, provided the original author and source are credited. 
degenerative changes are associated with development of degeneration in the hypertrophic myocardium. Significant role is also referred to coronarogenic myocardial lesions owing to advanced development of associated arteriosclerosis of coronary arteries which is presented as myocardium diffuse sclerosis and interstitial fibrosis. As the sequel of all causes above, Cardiac Failure (CF) develops and tends to remain one of the principal causes of death among such patients [4].

Degenerative changes of arterioles are associated with the response to vasculature infiltration by blood plasma proteins under the effect of high hydrostatic pressure and development of advanced arteriosclerosis. Major narrowing of the lumen in the afferent and efferent arterioles of kidneys results in dysfunction of glomeruli and tubules with gradual desolation and atrophy of the nephrons; sclerosis of connective tissues can also develop. Subsequently, nephrosclerosis (arteriosclerotic kidney) occurs which is a morphology substrate of Chronic Kidney Disease (CKD) [5].

Micro-aneurisms of small arteries are frequently observed in the brain being the leading causes of hemorrhagic stroke [6]

Narrowing of the whole arteriolar flow with enhanced correlation between diameters of venous and arterial vessels (more than 3:2 in ratio) is a primary sign of arteriosclerosis of eye retina. In cases of higher ranges of hypertension arterioles usually become irregular and alternation of narrow and dilated sites is remarkable. Exudates are concentrated around the arterioles which look like cotton wool and insult - a sequel of inconsistency of the vascular wall $[7,8]$.

Symptoms and signs of heart damage are related to the following:

\section{- Hypertrophy of the LV}

- Underlying Ischemic Heart Disease (IHD)

- CF which is a complication of both pathology processes [9].

The main aim of treatment performed in EmCell clinic is to decrease a total risk of cardiovascular diseases onset and death of patients due to decreased modifying factors of risk by means of non-medical and drugs-induced effects.

Medical drugs treatment must be initiated immediately when high and/or extremely high levels of risk are suspected in the patients with stable disease progression; similarly, it is also advised for the patients with moderate risks where persistent stabilization of $\mathrm{ABP}$ by use of non-medical options cannot be reached.

The principal medical methods of therapy regarded as effective in lowering mortality which is commonly caused by arterial hypertension and its complications could be split into 5 groups of medicines (first treatment of choice, grade A credibility evidence):

- Diuretics;

- $\beta$-adrenoreceptor antagonists;

- Angiotensin-Converting Enzyme (ACE) inhibitors;

- Calcium channel blockers;

- Angiotensin II receptor blockers (type 1).

Antihypertensive treatment is usually started with use of medicines above or their combinations.

Influence over different aspects of pathogenesis chain of arterial hypertension is considered to be an unequivocal benefit of such a therapy and, eventually, this contributes to more marked effects in majority of the patients with $\mathrm{AH}$.
In choice of combined therapy one must take into account all potential favorable and unfavorable effects which can appear after use of different treatment combinations [10,11].

In certain clinical situations and in circumstances when $A B P$ control is not possible, some supplementary groups of medicines might be administered along with the fundamental drugs of choice:

- $\alpha$-adrenoceptor antagonists;

- Imidazoline receptor agonists;

- Central alpha 2-adrenergic agonists [12].

However, a drawback of the above treatment methods is that these are not enough effective in treatment of $\mathrm{AH}$ due to insufficient effects upon blood pressure regulation; also they do not contribute to steady function of all systems in the patient and cannot recover proper vascular system in the patients, functions of the brain and heart vessels in particular.

Our objective was focused on improvement of treatment methods for essential AH by way of combination of "classical" therapy and preparations containing separated fetal stem cells (FSCs) without need of donor selection for major histocompatibility antigens. This approach helps to restore vessels micro damage at all levels and favors germination of new capillaries to replace the affected ones in regard to all organs which need additional trophic. As a result, ABP levels are stabilized and this contributes to improved functional capacity in the patients suffering from essential $\mathrm{AH}$; their life quality becomes better.

\section{Material and Methods}

In Cell Therapy Center EmCell 270 patients were treated since 2014 to 2016 including 193 patients suffering from essential AH. Among them 50 patients with stage II grade 3 essential $\mathrm{AH}$ were randomized. Allocation of all patients was made as follows: the MG was composed of 25 patients who were administered Fetal Stem Cells (FSCs) extracted from fetal liver; the second preparation included stem cells separated from fetal brain; and the third preparation constituted stem cells of fetal heart. All such patients received stem cell treatment against the background of conventional therapy; whereas the individuals in the Control Group (CG) who made up 25 patients suffering from stage II grade 3 essential AH underwent only standard therapy by use of antihypertensive medicines. All patients of the MG and CG were absolutely compared according to their age, sex, stage and grade of arterial hypertension.

Diagnosis of essential AH was established according to characteristic clinical pattern of the disease proven by the corresponding changes after physical examination as well as in accordance with the data of echocardiography studies (Echo ECG).

Age of the patients ranged from 37 to 64 years $(50.1 \pm 1.13$ yrs. on average). Among the patients who underwent treatment in the MG 14 patients were men $(56.0 \%)$ and 11 women $(44.0 \%)$ who had been administered the same treatment. An average persistence of essential AH disease in the patients constituted $7.6 \pm 0.54$ years, including a mean duration of treatment for $\mathrm{AH}$ which composed $6.3 \pm 0.55$ years.

25 patients of the CG suffering from essential AH were compared according to their age, sex, stage and grade of arterial hypertension with the patients in the MG who received transplanted FSCs.

A long-term standard therapy scheme was administered for the patients of both groups who suffered from $\mathrm{AH}$ disease in accordance with all generally accepted recommendations of the European Society 
of Cardiologists (2013): $\beta$-adrenoreceptor antagonists (carvedilol in average dose of $58.2 \pm 4.9 \mathrm{mg}$ ), diuretics (indapamide in average dose of $1.52 \pm 0.34 \mathrm{mg}$ ), angiotensin-converting enzyme (ACE) inhibitors (perindopril arginine in average dose of $6.5 \pm 0.7 \mathrm{mg}$ ) and/ or angiotensin II receptor blockers (ARB) (valsartan in average dose of $10.0 \pm 10.5 \mathrm{mg}$ ), calcium channel blockers (amlodipine in average dose of $4.8 \pm 0,4 \mathrm{mg}$ ) with individual adjustment of the drugs dose (Table 1 ).

On the background of standard treatment which was continuously administered, suspensions containing separated FSCs were used in complex treatment for the patients in the MG who signed informed consent and their agreement was obtained prior to FSCs therapy. This study was approved by the local ethics committee which had been established at Kyiv City Clinical Emergency Hospital being located on the address: 3 Bratyslavska str., Kyiv City, Ukraine.

For treatment of patients in the MG we used cryopreserved suspensions containing pluripotent FSCs. Suspensions were prepared from cadaveric human embryos with 7-12 weeks of gestation which included isolated FSCs; material was collected in conformity with legislation following the planned abortions in women owing to social or family planning reasons. Withdrawal of abortive material was performed in conformity with all ethical-moral and legal principles of work with biological tissues. All donors were practically healthy, the women underwent screening for hemic infections - all test results were negative in all women.

One suspension was made of hematopoietic stem cells derived from fetal liver, while the other were prepared using isolated stem cells of fetal brain and heart. Biotechnology process to prepare suspensions consisted in stem cells separation from different growth zones of cadaveric human fetus after a corresponding evaluation of stem cells viability along with their programmed cryopreservation and screening at the independent laboratories by means of virology and bacteriology studies.

Harvesting of the fetal material was made in the surgery premises by means of generally accepted aseptic and antiseptic techniques. Separation of tissues was performed using embryonic liver, heart and brain tissues extracted from human fetuses 7-12-weeks of gestation upon the written informed consent received from the pregnant women, who were going to initiate a medical abortion because of family planning or social reasons; no infections or abnormal embryo development were reported in such donors. After that fetal tissue was placed into a sterile transport medium which was made of Hanks solution and an antibiotic. All extracted tissues were exposed to separation according to the aseptic rules to be furtherly homogenized in Hanks solution.

Cryopreservation was performed by application of 5\% Dimethyl Sulfoxide (DMSO) as cryoprotectant and dextran- 40 according to the 3 -stage cryopreservation program with start velocity of $1{ }^{\circ} \mathrm{C} / \mathrm{min}$ and initiation of crystal forming. Viability of stem cells in suspensions prior to application was controlled by use of trepan blue staining. Calculation

\begin{tabular}{|c|c|c|}
\hline Medicine & & \\
\hline & Main group & Control group \\
\hline Carvedilol, $\mathrm{n}$ & 11 & 14 \\
\hline Indapamide, $\mathrm{n}$ & 17 & 16 \\
\hline Perindopril arginine, $\mathrm{n}$ & 19 & 13 \\
\hline Valsartan, $\mathrm{n}$ & 6 & 9 \\
\hline Amlodipine, $\mathrm{n}$ & 9 & 8 \\
\hline
\end{tabular}

*- $n$ : number of patients who followed standard therapy using a definite drug

Table 1: Standard treatment for the patients with arterial hypertension. was performed in parallel using Goryaev chamber and automated cell counter (1450001 TC10 TM Automated Cell Counter)

Prior to freezing stem cells viability in a suspension constituted $83.0 \pm 3.0 \%$. After storage at the low temperature cryobank $\left(\mathrm{t}-196^{\circ} \mathrm{C}\right)$ and following suspension defrost in a water bath at temperature +37.5 $\pm 0.12^{\circ} \mathrm{C}$ stem cells viability rate constituted not less than $74.8 \pm 1.03 \%$.

To inspect a safety of preparations both pregnant women and harvested hematopoietic stem cells from the fetal liver were controlled for bacterial and fungal, parasitic and viral infections: hepatitis $\mathrm{B}$ virus, hepatitis $\mathrm{C}$ virus, HIV 1 and HIV 2, herpes simplex virus type 1 and 2, rubella, Epstein-Barr virus, cytomegalovirus, toxoplasmosis (toxoplasma gondii), syphilis (treponema pallidum), ureaplasma parvum, chlamydia trachomatis, ureaplasma urealyticum, and mycoplasma genitalium.

All suspensions with hematopoietic stem cells harvested from fetal liver, brain and heart were cryopreserved in liquid nitrogen using a specially equipped cryobank at $-196^{\circ} \mathrm{C}$.

Stem cell procedure consisted in transplantation of the suspension containing cryopreserved FSCs following a conventional premedication by use of infusions with diphenylhydramine $10 \mathrm{mg}$ and prednisone 15 mg on day 1 and a specially prepared solution on day 2 .

During the treatment day 1, we administered hematopoietic stem cells from fetal liver which were harvested from the tissues of 7-12-week-old human fetuses. A suspension containing cryopreserved hematopoietic stem cells was administered using an intravenous dripfeed in the amount of $0.15 \pm 0.01 \mathrm{~mL}$ with nucleated cell count of $41.28 \times 10^{6} / \mathrm{mL}$ per transplantation.

On treatment day 2 , we used ectodermal homogenate containing precursors of nervous cells subcutaneously, in the amount of $0.52 \pm$ $0.19 \mathrm{~mL}$ with nucleated cell count of $5.81 \times 10^{6} / \mathrm{mL}$ per transplantation.

During the third day of treatment homogenate containing precursors of heart cells in the amount of $0.62 \pm 0.04 \mathrm{~mL}$ with nucleated cell count of $2.73 \times 10^{6} / \mathrm{mL}$ per transplantation was administered by means of subcutaneous injections.

In addition, prior to administration of suspensions supplementary control of stem cell preparations with fetal liver, fetal brain and heart was conducted; in particular, microscopic study had been performed along with stem cells viability testing by use of automated cell counter.

CD34+ cells were calculated using flow cytofluorometry method (Becton Dickinson, Franklin Lakes, NJ, USA) with fluorescent tagged antibodies (Santa Cruz Biotechnology, Dallas, TX, USA) [13-15].

Culturing was performed inside of 24-hole trays in atmosphere with $5 \% \mathrm{CO}_{2}$ and $100 \%$ humidity at $37^{\circ} \mathrm{C}$ in the next semisolid medium: agar 33\% (Difco; Becton Dickinson), glutamine $4.0 \mathrm{mM} / \mathrm{L}$ (Sigma-Aldrich, St Louis, MO, USA), penicillin-streptomycin (100 U $+100 \mathrm{mcg} / \mathrm{mL}$ ) (Sigma-Aldrich), granulocyte-macrophage colonystimulating factor $100 \mathrm{U} / \mathrm{mL}$ (Sigma-Aldrich), interleukin $3100 \mathrm{U} /$ $\mathrm{mL}$ (Behringwerke AG, Marburg, Germany), stem cell factor $50 \mathrm{ng} /$ $\mathrm{mL}$ (R\&D Systems, Minneapolis, MN, USA), and erythropoietin $10 \mathrm{U} /$ $\mathrm{mL}$ (epoetin beta; Boehringer Manheim Pharmaceuticals, Ingelheim, Germany). All media were prepared using Dulbecco's Modified Eagle's Medium (PAA Laboratories GmbH, Pasching, Austria). Within the colonies (CFU-E [colony-forming unit erythrocyte], CFU-GM [colonyforming unit granulocyte monocyte], and CFU-GEMM [colony forming unit-granulocyte, erythrocyte, monocyte, megakaryocyte) a calculation of their amounts and type was performed on the $14^{\text {th }}$ day of culture growth. 
Progenitor cells, stem cells of fetal brain and heart tissue were specially cultured in vitro. Thus, neurospheres were formed and, therefore, their number pointed at functional potential of fetal neural stem cells to promote subsequent use of them. Heart received from the aborted material was separated from the other fetal tissues, washed off caked blood and rinsed in Hank's solution and antibiotics. Then it was placed into the tissue grinder with subsequent application of Hank's solution for homogenizing. Cryo-ampoules were used for storage by cryoprotective agent and obtained material was exposed to freezing according to the conventional program of cryopreservation.

Prior to stem cell treatment, over 1, 3 and 6 months after stem cells therapy all patients underwent general clinical examination: common blood count, urine testing and blood biochemistry investigations. The parameters of Glomerular Filtration Rate (GFR), Pulse Wave Velocity (PWV), Left Ventricular Myocardial Thickness (LVMT), Systolic Blood Pressure (SBP) and Pulse Pressure (PP) were defined in the patients; ECG and echocardiography investigations were performed for such patients respectively.

After transplantation of suspensions containing stem cell of fetal liver, brain and heart, the patients of the MG reported no single case of complications: neither allergic reaction, nor adverse effects including "graft-vs-host" disease. Statistical values and significant differences were processed using Statistica v.8.0.

\section{Results}

Tendency to improve in the parameters under study as decreased SBP and pulse pressure, LV wall thinning, increased GFR and PWV have been revealed during our observation (Table 2).

In this regard the value of systolic Arterial Blood Pressure (SBP) in patients of the MG decreased by $6.9 \%$ over 1 month after FSCs transplantation $(\mathrm{p}<0.05$, compared to the baseline); over 3 months - was lower by $16.2 \%$ ( $<<0.05$, vs. baseline), and over 6 months after FSCs treatment it was reduced by $21.5 \%$, which is significantly less than the same parameter prior to treatment ( $<<0.001$, vs. baseline). In CG patients who were administered conventional therapy alone, improvement has been recorded too; however, these effects tend to be less marked in this group of patients. From this perspective, figures of SBP over 1 month after therapy reduced by $2.3 \%$ without statistically reliable significance; whereas over 3 months these values decreased by $4.7 \%(\mathrm{p}<0.05)$, and over 6 months - by $8.4 \%(\mathrm{p}<0.05)$. Difference between the groups was defined as significant over 3 months after beginning of observation; the ranges of SBP in the patients of the MG were decreased by $29 \%(\mathrm{p}<0.05)$, compared to the patients in the CG, and in view of this such parameters were reduced by $39 \%$ over 6 months after FSCs therapy $(\mathrm{p}<0.001)$. Therefore, levels of SBP over 3 and 6 months after FSCs therapy remained significantly better among the patients of both groups; nevertheless, remarkable changes of this parameter were demonstrable as early as over 1 month after FSCs administration in the group of patients treated by suspensions containing stem cells of fetal liver, brain and heart. On top of that, the patients of the MG reported improved functional capacity which was markedly more intense.

Similar changes were also recorded after analysis of the PP values. Significant improvements of pulse pressure among the patients of the MG have been already observed after the first month of treatment as well as characteristic reduction in PP by $12.5 \%$ was recorded $(\mathrm{p}<0.05)$; the same value was lower by $16.6 \%(\mathrm{p}<0.05)$ over 3 months, and over 6 months after FSCs treatment this level was reduced by $19.2 \%$ $(p<0.001)$ compared to the baseline parameters. In the CG the same rates also demonstrated a tendency to downgrading: over 1 month after treatment PP level decreased by $2.8 \%$, over 3 months - by $5.0 \%$, and after 6 months - it was lower by $7.8 \%$ respectively; however, statistical significance was unremarkable for this group of patients. In addition, as early as 1 month after treatment the patients in the MG reported significant improvement in PP value (pulse pressure was reduced) in comparison with the patients of the CG. Over 1 month after treatment a corresponding difference between these groups made up $77.6 \%$ $(\mathrm{p}<0.05)$; over 3 months it constituted $69.9 \%(\mathrm{p}<0.05)$, and after 6 months such a difference was $-59.3 \%(\mathrm{p}<0.05)$.

In respect to the indices of LVMT, a significant decrease in the MG patients was observed after the 3rd month of follow-up only reduced LVMT by $12.7 \%(\mathrm{p}<0.05)$, but over 6 months - it decreased by $20.7 \%(p<0.001)$, versus the baseline. Besides, rates of LV myocardial thickness over 6 months were significantly lower in the MG patients - 9.2\% $(p<0.05)$, compared to the same values over 3 months of observation. Values of LVMT before treatment and over 1 month after treatment in CG patients were not recorded as significant; however, over the period of 3 months this parameter of the LV was reduced by $7.6 \%(\mathrm{p}<0.05)$, and LVMT after 6 months under observation was less by $9.7 \%(p<0.05)$. If compared between the patients of the MG and the CG difference in intensity of LV myocardial thickening was remarkable already over 1 month under the study: LVMT degraded by $8.2 \%(\mathrm{p}<0.05)$ in the patients of the MG, over 3 months it was less by $6.9 \%(\mathrm{p}<0.05)$, and over 6 months - was lower by $8.5 \%(\mathrm{p}<0.05)$.

The score of GFR in the MG patients had significant improvement over 3 months: there was elevation in GFR by $8.8 \%(\mathrm{p}<0.05)$; whereas over 6 months this value was higher by $23.4 \%(\mathrm{p}<0.001)$. The patients

\begin{tabular}{|c|c|c|c|c|c|c|c|c|}
\hline Study & $\begin{array}{c}\text { MG before } \\
\text { treatment }\end{array}$ & $\begin{array}{l}\text { CG before } \\
\text { treatment }\end{array}$ & $\begin{array}{l}\text { MG over } \\
1 \text { month }\end{array}$ & $\begin{array}{l}\text { CG over } \\
1 \text { month }\end{array}$ & $\begin{array}{l}\text { MG over } \\
3 \text { months }\end{array}$ & $\begin{array}{l}\text { CG over } \\
3 \text { months }\end{array}$ & $\begin{array}{l}\text { MG over } \\
6 \text { months }\end{array}$ & $\begin{array}{l}\text { CG over } \\
6 \text { months }\end{array}$ \\
\hline SBP, mm.Hg. M $\pm m$ & $163.9 \pm 12.2$ & $163.1 \pm 12.5$ & $152.5 \pm 15.0^{*}$ & $159.3 \pm 17.10$ & $137.4 \pm 14.2^{*}$ & $155.5 \pm 16.3 \#$ & $128.6 \pm 13.9^{* * \$}$ & $149,4 \pm 15,8^{*} \# \#$ \\
\hline $\mathrm{PP}, \mathrm{mm} \cdot \mathrm{Hg} \cdot \mathrm{M} \pm \mathrm{m}$ & $72.5 \pm 16.9$ & $75.3 \pm 17.4$ & $63.4 \pm 15.0^{*}$ & $73.2 \pm 17.1 \#$ & $60.4 \pm 14.2^{*}$ & $71.5 \pm 16.3 \#$ & $58.6 \pm 13.9^{* *}$ & $69.4 \pm 15.8^{\star} \#$ \\
\hline LVMT, cm, (Echo ECG data) M $\pm m$ & $1.50 \pm 0.04$ & $1.44 \pm 0.06$ & $1.46 \pm 0.08$ & $1.34 \pm 0.04 \#$ & $1.31 \pm 0.06^{*}$ & $1.33 \pm 0.05^{\star} \#$ & $1.19 \pm 0.01^{* *} \$$ & $1.30 \pm 0.04^{*} \# \#$ \\
\hline GFR, mL/min & $88.7 \pm 2.94$ & $89.1+2.88$ & $90.1+2.87$ & $90.89+0.26$ & $96.5+2.39^{*}$ & $91.82+0.25$ & $109.5+1.62^{* * \$}$ & $94.23 \pm 0.33^{*} \#$ \\
\hline PWV, m/s & $7.4 \pm 0.3$ & $7.7 \pm 0.6$ & $8.1 \pm 0.6$ & $8.2 \pm 0.8$ & $10.1 \pm 1.2^{*}$ & $8.4 \pm 0.9$ & $12.3 \pm 1.4^{\star *}$ & $10.4 \pm 1.7^{*}$ \\
\hline
\end{tabular}

* p $<0.05$ - clinical accuracy between the values in the MG and the CG before and after treatment using FSCs; ${ }^{* *}$ p $<0.001-$ significance between the parameters in the $M G$ and the CG before and after treatment;

$\$-p<0.05$ - significance between the values over 3 months and 6 months after treatment using suspensions of stem cells extracted from fetal liver, fetal brain and heart \#- $p<0.05$ - clinical accuracy between the parameters after conventional treatment and therapy by use of stem cells extracted from fetal liver, fetal brain and heart \#\#- $p<0.001$ - significance between the values after conventional treatment and therapy by use of stem cells extracted from fetal liver, fetal brain and heart Notes: SBP: Systolic Blood Pressure; PP: Pulse Pressure; LVMT: Left Ventricular Myocardial Thickness; GFR: Glomerular Filtration Rate; PWV: Pulse Wave Velocity; Echo ECG: Echocardiography

Table 2: Changes of parameters after complex clinical evaluation and assessment of morphology functional state of LV ventricle in the patients with essential arterial hypertension of the main and control groups. 
who received suspensions containing stem cells of fetal liver, brain and heart along with their standard treatment reported significantly higher GFR if compared to the results over 3 and 6 months where this value raised by $13.5 \%(\mathrm{p}<0.05)$. An increase of GFR among the CG patients was only observed over 6 months after conventional therapy and this index was enhanced by $2.6 \%(\mathrm{p}<0.05)$. In MG patients over a period of 6 months after suspensions containing stem cells of fetal liver, brain and heart were administered simultaneously with standard treatment we observed more significant elevation in the score of GFR in comparison with the patients of the CG who had GFR elevation by $16.2 \%(\mathrm{p}<0.05)$.

Parameters of PWV in the MG patients were significantly higher only over the study period of 3 months post therapy: these scores increased by $36.4 \%(\mathrm{p}<0.05)$, and over 6 months the same value was higher by $66.2 \%(p<0.001)$. Whereas the patients of the CG demonstrated significant elevation of PWV value as late as over 6 months after conventional treatment by $35.1 \%(\mathrm{p}<0.05)$. There was no significant difference in PWV parameters in the MG patients compared to the CG, (all $\mathrm{p}>0.05)$.

In consequence, after administration of suspensions containing stem cells of fetal liver, brain and heart all patients with essential $\mathrm{AH}$ reported positive dynamics of changes in the parameters of their clinical condition - according to both objective and subjective values. Over 6 months after treatment by use of suspensions containing stem cells of fetal liver, brain and heart we observed significant increase in GFR by $23.4 \%(\mathrm{p}<0.001)$ and PWV values were higher by $66.2 \%(\mathrm{p}<0.001)$. In addition, patients sustained a significant decrease in SBP results - by $21.5 \%,(\mathrm{p}<0.001$, versus the baseline) and PP score revealed a decrease by $19.2 \%(p<0.001)$. The patients also reported significant reduction of LVMT - it was thinner by $20.7 \%(\mathrm{p}<0.001)$.

After comparative study of the scores between the patients in the MG and CG, changes in values of functional capacity and morphologyfunctional condition of the LV myocardium were also remarkable. Decrease of SBP in the patients under study was significant over 3 months, and over 6 months after treatment this difference became even more expressed. In regard to changes of PP values the patients of the MG already after the 1st month had a significant decrease in pulse pressure, in comparison with the same in the CG; such a difference continued its growth both over 3 and 6 months after treatment. The patients of the MG compared to the CG demonstrated difference in intensiveness of LVMT as early as over 1 month after follow-up and this difference became more marked with timespan. A more significant increase of GFR was observed in the MG patients who underwent treatment by use of suspensions containing stem cells of fetal liver, brain and heart compared to the patients in the CG $(\mathrm{p}<0.05)$ after GFR changes were evaluated over a period of 6 months against the background of standard treatment. No significant difference was reported in the patients of the MG when we assessed improvements in PWV parameters compared to the data among CG patients, all $(\mathrm{p}>0.05)$.

\section{Discussion}

It has been established that at the expense of at least 3 suspensions administered containing cryopreserved FSCs and by virtue of a count of nucleated cells per $1 \mathrm{~mL}$ of suspension along with the standard therapy we attained a meaningful effect on the morphology-functional state of the LV which contributed to better regulation of vascular tone and heart contractile function in particular; systolic function of the LV myocardium is improved owing to a large number of contractile cellular elements inside of myocardium and/or by means of elevation of functional reserves of cardiomyocytes in the recipient because of better stimulation of intracellular regeneration processes in them. Simultaneously, kidney excretory function becomes intense, and as a result, patient's Circulating Blood Volume (CBV), Cardiac Output (CO) and Total Peripheral Resistance (TPR) are reduced. In addition, stem cells after their entry into the organism start releasing angiogenic and anti-inflammatory factors as well as start replacement of the affected cells of the vascular system; they also tend to restore vascular micro damages at different levels and contribute to budding of the new capillaries instead of those affected within all organs which require supplementary nourishment and; subsequently, a regeneration of vasculature in human takes place. This will allow us making a work of all systems concord and therapy contributes to recovery of functions within the vessels of brain and heart by means of improved elasticity and permeability properties of the vessels. In consequence, BP levels are stabilized and this contributes to better functional condition in the patients with essential $\mathrm{AH}$ and their overall life quality is improved. In concurrence with this, a necessity of donor choice based on histocompatibility antigens is fully excluded and we have opportunity for repeated administrations of suspensions containing stem cells of fetal liver. Furthermore, premedication prior to treatment by suspensions containing fetal liver stem cells is made to prevent chances of allergic reactions in the patients. Specifically, a use of 3 suspensions of FSCs simultaneously with conventional (medicines) treatment as mentioned above contributes to better effects of therapy among all patients with essential $\mathrm{AH}$ : clinical signs of $\mathrm{AH}$ and its complications are reduced, as well as the other findings were lower if supplementary assessment is performed.

Application of stem cells extracted from fetal liver, brain and heart to be used for FSCs suspensions preparing is stipulated by their plasticity, in particular, because of property of stem cells to induce replacement and differentiation in response to external affection or in conformity with internal program in FSCs. Stem cells have been known to preserve their potential to growth, regeneration, differentiation, migration and recovery of all links with the other cells. In comparison with cells of mature tissues FSCs have better ability to proliferate [1618]. Administration of FSCs is also effective because of their ability to form a range of growth factors. For instance, stem cells of fetal liver can produce a great number of stimulating substances like various angiogenic and neurotrophic factors which contribute to stem cells survival and growth, proliferation and differentiation; these cells are well-learned to stimulate regeneration on account of host cells which are surrounding them $[19,20]$.

Besides, FSCs can survive at the lower levels of oxygenation compared to already differentiated cells and this makes them resistant to ischemic lesions - both during in vitro manipulations, and after intravenous administration of such stem cells [21]. Proliferative or immature stem cells of fetal liver predominantly do not have long processes or not enough powerful intercellular adhesion and, therefore, these cells are exposed to less destruction during a process of preparation of fetal stem cell suspensions. Such characteristic features allow us to administer stem cells of fetal liver in a mode of suspensions for i.v. infusion. The above presented characteristics can easily explain enhanced viability of FSCs and fetal tissues compared to adult stem cells if they are immediately cryopreserved [22-24].

Experimental use of human embryonic material stipulates a lot of disputes and challenges. Use of embryonic (fetal) human tissues is not supported and even became illegal in many countries; among those countries are the USA and European Union. As for the other countries (Ukraine is also among them) this biological material can be used for experimental treatment purposes after a woman makes her social 
Citation: Klunnyk MO, Sych NS, Matiyashchuk IG, Sinelnyk AA, Ivankova OV, et al. (2016) Use of Stem Cell Suspensions containing Separated Fetal Stem Cells in Complex Treatment of Patients with Essential Hypertension. J Stem Cell Res Ther 6: 366. doi: 10.4172/2157-7633.1000366

Page 6 of 7

decision to abort and signs an informed consent for donating fetal tissues in accordance with all ethics, moral and legal principles. There are many opponents of aborted human embryos to be used for treatment purposes which, as believed, can raise a "demand" in abortions. However, in our epoch of feminization, when predominant population of women are working and even hold top management positions they still wish to plan their own life and are free to decide about suitable time for child bearing. Therefore, a problem of abortions still exists and will be contemporary despite of exclamations from separate political and religious organizations. On account of a real value of fetal material, and with consideration of its enormous properties and potential to help a number of people, even in circumstances of incurable diseases, it would be inhumane to leave out such an opportunity to save one's life or improve life quality of the other people. Taking into account our not so great, however, rather optimistic experience in use of FSCs, capable to transform into functional specialized cells within different body tissues, scientists lay their great hopes and expectations on FSCs effective use in clinical practice.

Along with this, there are fears of some experts regarding possible unfavorable side effects of stem cell therapy. There are some data in literature [25-27], regarding inappropriate differentiation of cells where, as they think, stem cells use can result in tumor (teratoma). During this study we administered FSCs only, which cannot exert oncogenic properties and within the whole period of our practice we did not experience likely processes among the patients. One more possible effect in human after FSCs transplantation is a potential to reject stem cells; however, since HLA receptors are immature in embryonic fetuses of 7-12 weeks of gestation [28,29]; such a graft-versus-host reaction is not the case. No similar cases were recorded based on general clinical criteria during our study either. It is worth to conclude that traditional antihypertensive therapy with inclusion of FSCs is a perspective and safe method of complex treatment for the patients with essential AH.

All data which we gathered are much likely encouraging with regard to a complex treatment of the patients with essential AH using a standard therapy in combination with transplantation of FSCs. From this perspective it is too early to raise any idea about value of FSCs use for prevention of apoptosis of human cardiomyocytes; however, one may believe all future scientific studies will ultimately explicate this aspect of FSCs effects on a favorable course and prognosis of essential $\mathrm{AH}$.

\section{Conclusions}

Over 6 months after complex treatment the patients with essential $\mathrm{AH}$ who were administered suspensions of isolated stem cells of fetal liver, brain and heart along with their standard therapy reported a significant elevation of GFR rates by $23.4 \%(\mathrm{p}<0.001)$ and PWV by $66.2 \%(\mathrm{p}<0.001)$.

$>$ Over 1, 3 and 6 months after FSCs treatment significant reductions of SBP ranges by $21.5 \%$, $(\mathrm{p}<0.001$, vs. the baseline) and PP rate by $19.2 \%(p<0.001)$ have been recorded among the patients. LV became thinner by $20.7 \%$ which was significant for the patients under study too $(\mathrm{p}<0.001)$.

$>$ It has been established that FSCs transplantation is a safe and effective method of treatment and could be used in complex therapy along with conventional medicines commonly used for the patients with AH. This treatment method inspires great hopes; however, it still demands the controlled and randomized clinical trials in future.

\section{References}

1. Lifton RP, Gharavi AG, Geller DS (2001) Molecular mechanisms of human hypertension. Cell 104: 545-556. [PubMed]

2. Enright PL, Sherill DL (1998) Reference equations for the six-minute walk in healthy adults. Am J Respir Crit Care Med 158: 1384-1387. [PubMed]

3. Evans MJ, Kaufman MH (1981) Establishment in culture of pluripotential cells from mouse embryos. Nature 292: 154-156. [PubMed]

4. Kamihata $H$, Matsubara $H$, Nishiue $T$, Fujiyama S, Tsutsumi $Y$, et al. (2001) Implantation of bone marrow mononuclear cells into ischemic myocardium enhances collateral perfusion and regional function via side supply of angioblasts, angiogenic ligands, and cytokines. Circulation 104: 1046-1052. [PubMed]

5. Feigenbaum H (1994) Echocardiography. 5th Ed. Philadelphia: Lea \& Febiger p: 675.

6. Cuspidi C, Ambrosioni E, Mancia G, Pessina AC, Trimarco B, et al. (2002) Role of echocardiography and carotid ultrasonography in stratifying risk in patients with essential hypertension: the Assessment of Prognostic Risk Observational Survey. J Hypertens 20: 1307-1314. [PubMed]

7. Jensen JS, Feldt-Rasmussen B, Strandgaard S, Schroll M, Borch-Johnsen $\mathrm{K}(2000)$ Arterial hypertension, microalbuminuria and risk of ischemic heart disease. Hypertension 35: 898-903. [PubMed]

8. Menasche P, Hagege A, Scorsin M, Pouzet B, Desnos M, et al. (2001) Myoblast transplantation for heart failure. Lancet 357: 279-280. [PubMed]

9. Le Blanc K, Ringdén O (2005) Immunobiology of human mesenchymal stem cells and future use in hematopoietic stem cell transplantation. Biol Blood Marrow Transplant 11: 321-334. [PubMed]

10. Nichols WW, O'Rourke MF (1990) Aging, high blood pressure and disease in humans. In: Arnold E., editor. McDonald's Blood Flow in Arteries: Theoretical, Experimental and Clinical Principles. 3rd ed. London/Melbourne/Auckland: Lea and Febiger pp: 398-420.

11. Hansson L, Zanchetti A, Carruthers SG, Dahlof B, Elmfeldt D, et al. (1998) Effects of intensive blood-pressure lowering and low-dose aspirin in patients with hypertension: principal results of the Hypertension Optimal Treatment (HOT) randomised trial. HOT Study Group. Lancet 351: 1755-1762. [PubMed]

12. Orlic D, Kajstura J, Chimenti S, Jakoniuk I, Anderson SM, et al. (2001) Bone marrow cells regenerate infarcted myocardium. Nature 410: 701-705. [PubMed]

13. Petrenko AY, Khunov YA, Ivanov YN (2001) Stem cells. Properties and clinical perspectives. Luhansk, Ukraine: Press Express pp. 224-239. [PubMed]

14. Pittenger MF, Mackay AM, Beck SC, Jaiswal RK, Douglas R, et al. (1999) Multilineage potential of adult human mesenchimal stem cells. Science 284 143-147. [PubMed]

15. Potapov IV, Bashkina LV, Zaydenov VA (2002) Effect of embryonic cardiomyocytes and mesenchymal cell transplantation on contractile function of the heart in experimental myocardial infarction. Bull Transplantol Artif Organ 3: 88-89.

16. Taupin P (2008) Stem cells and regenerative medicine. In: Pharmacology and therapy. Vol. III. New York: Nova Science Publishers p: 135.

17. Tomita S, Li RK, Weisel RD, Mickle DA, Kim EJ, et al. (1999) Autologous transplantation of bone marrow cells improves damaged heart function. Circulation 100: 247-256. [PubMed]

18. Wang JS, Shum-Tim D, Galipeau J, Chedrawy E, Eliopoulos N, et al. (2000) Marrow stromal cells for cellular cardiomyoplasty: Feasibility and potential clinical advantages. J Thorac Cardiovasc Surg 120: 999-1006. [PubMed]

19. Klahr S, Levey AS, Beck GJ, Caggiula AW, Hunsicker L, et al. (1994) The effects of dietary protein restriction and blood-pressure control on the progression of chronic renal disease. Modification of Diet in Renal Disease Study Group. N Engl J Med 330: 877-884. [PubMed]

20. Turnbull F, Neal B, Algert C, Chalmers J, Chapman N, et al. (2005) Effects of different blood pressure-lowering regimens on major cardiovascular events in individuals with and without diabetes mellitus: results of prospectively designed overviews of randomized trials. Arch Intern Med 165: 1410-1419. [PubMed]

21. Makino S, Fukuda K, Miyoshi S, Konishi F, Kodama H, et al. (1999) Cardiomyocytes can be generated from marrow stromal cells in vitro. J Clin Invest 103: 697-705. [PubMed] 
Citation: Klunnyk MO, Sych NS, Matiyashchuk IG, Sinelnyk AA, Ivankova OV, et al. (2016) Use of Stem Cell Suspensions containing Separated Fetal Stem Cells in Complex Treatment of Patients with Essential Hypertension. J Stem Cell Res Ther 6: 366. doi: 10.4172/2157-7633.1000366

22. Asger A, Møller JM, Daugaard PC, Kjær SU, Erik S (2008) Effects of phosphodiesterase-5 inhibition by sildenafil in the pressure overloaded right heart. Eur J Heart Fail 10: 1153-1157. [PubMed]

23. Ohno N, Fedak PW, Weisel RD, Komeda M, Mickle DA, et al. (2002) Cell transplantation in non-ischemic dilated cardiomyopathy. A novel biological approach for ventricular restoration. Jpn J Thorac Cardiovasc Surg 50: 457460. [PubMed]

24. Stears AJ, Woods SH, Watts MM, Burton TJ, Graggaber J, et al. (2012) A double-blind, placebo-controlled, crossover trial comparing the effects of amiloride and hydrochlorothiazide on glucose tolerance in patients with essential hypertension. Hypertension 59: 934-942. [PubMed]

25. Sakakibara Y, Tambara K, Lu F, Nishina T, Sakaguchi G, et al. (2002) Combined procedure of surgical repair and cell transplantation for left ventricular aneurysm: An experimental study. Circulation 106: 193-197.
26. Strauer BE, Brehm M, Zeus T, Köstering M, Hernandez A et al. (2001) Repair of infarcted myocardium by autologous intracoronary mononuclear bone marrow cell transplantation in humans. Nat Med 7: 430-436. [PubMed]

27. Wang JS, Shum-Tim D, Chedrawy E, Chiu RC (2001) The coronary delivery of marrow stromal cells for myocardial regeneration: Pathophysiologic and therapeutic implications. J Thorac Cardiovasc Surg 122: 699-705. [PubMed]

28. Tomita S, Mickle DAG, Weisel RD, Jia ZQ, Tumiati LC, et al. (2002) Improved heart function with myogenesis and angiogenesis after autologous porcine bone marrow stromal cell transplantation. J Thorac Cardiovasc Surg 123 1132-1140. [PubMed]

29. Boutouyrie P, Achouba A, Trunet P, Laurent S (2010) Amlodipine-valsartan combination decreases central systolic blood pressure more effectively than the amlodipine-atenolol combination: the EXPLOR study. Hypertension 55: 1314-1322. [PubMed] 